В. В. Тюньков

Иркутский государственный университет путей сообщения, г. Иркутск, Российккая Федерация

Л. В. Санина

Байкальский государственный университет, г. Иркутск, Российккал Федерация

Е. Г. Санникова

Иркутский государственный университет путей сообщения, г. Иркутск, Российская Федерация

\title{
РИСК-МЕНЕДЖМЕНТ В СИНЕРГЕТИКЕ УЧЕБНОГО ПРОЦЕССА НА СТАРШИХ КУРСАХ УНИВЕРСИТЕТА ПРИ ПОДГОТОВКЕ ИНЖЕНЕРОВ-СПЕЦИАЛИСТОВ
}

\begin{abstract}
АНнотАЦия. В статье представлены промежуточные результаты постановки проблемы исследования процесса адаптации сферы образовательных услуг к федеральному государственному образовательному стандарту третьего поколения, который базируется на компетентностном подходе в освоении комплекса дисциплин учебного плана, с одной стороны, и более полной реализации потенциала выпускаемых специалистов, в том числе соответствия конкретной профессиограмме, с другой. Рассматриваются параметры профессионального обучения как системы, которая находится под воздействием интенсивного инновационного развития производства, транснациональной специализации и конкуренции. Для систем такого типа важна синергетическая компонента, где, по мнению ведущих отечественных исследователей, в целом синергетику как научную парадигму и нелинейный стиль мышления можно охарактеризовать несколькими позициями, коррелирующими с эволюцией (поколениями) систем, допускающим многовариантность, а также их структуры и управления, зависимыми от процессов на вышележащих или нижележащих уровнях. Таким образом, при желании управлять такой системой (возникающими конфликтами) потребуются прецизионные воздействия, формирующие элементы стабильной мотивации организационного процесса предварительно апробированного характера.

кЛючЕВЫЕ СЛОВА. Информация; теории информации; информационное взаимодействие; виды и свойства информации; информационный ресурс.

ФИНАНСИРОВАНИЕ. Государственное задание № 26.1348.2014/К на выполнение научно-исследовательских работ в сфере научной деятельности в рамках проектной части, проект № 1348 «Влияние теневого сектора экономики на качество жизни населения в России и Украине: сравнительный анализ» (номер госрегистрации в ФГАНУ ЦИТиС 114091140015).

ИНФОРМАЦИЯ О СТАТЬЕ. Дата поступления 3 марта 2016 г.; дата принятия к печати 17 июня 2016 г.; дата онлайн-размещения 31 июля 2016 г.
\end{abstract}

V. V. Tyunkov

Irkutsk State Railway Engineering University, Irkutsk, Russian Federation

L. V. Sanina

Baikal State University, Irkutsk, Russian Federation

E. G. Sannikova

Irkutsk State Railway Engineering University, Irkutsk, Russian Federation

\section{RISK MANAGEMENT IN SYNERGETICS OF EDUCATIONAL PROCESS FOR UNIVERSITY SENIOR STUDENTS IN TRAINING SPECIALISTS IN ENGINEERING}

ABSTRACT. The article presents intermediate results of setting a problem of researching the process of adapting the educational services to the governmental educational sphere

\section{Baikal Research Journal}


of the third generation which is built on the competence-based approach to mastering a complex of academic disciplines, on the one hand, and on more complete implementation of graduate specialists' potential, including the conformity of a specific prefessiogram, on the other hand. It considers the parameters of professional training as a system which experiences an effect of intensive innovative production development, transnational specialization and competition. For the systems of this type of certain importance a synergetic component where, according to leading national researchers, on the whole, synergetics, as a scientific paradigm and a non-linear style of thinking, can be characterized by several positions that correlate with evolution (generations) of systems allowing multivariance, as well as their structure and management that are dependent on the processes at superjacent or subjacent levels. Thus, the desire to manage this system requires precious effects that form the elements of stable motivation of an organizational process of preliminarily approved character.

KEYWORDS. Information; theory of information; information interaction; types and properties of information; information resource.

FINANCING. This article was written with the financial support from State task № 26.1348.2014/K for research, Project № 1348 «Influence of shadow economy on the quality of life of the population in Russia and Ukraine: comparative analysis» (number of state registration at the Federal Center of Information Technology and Systems 114091140015). ARTICLE INFO. Received March 3, 2016; accepted June 17, 2016; available online July $31,2016$.

Переход на старшие курсы университета подтверждает завершение освоения блока дисциплин общефедеральной компоненты учебного плана и характеризуется усилением тесноты связи студента с предполагаемым рабочим местом, о котором получены конкретные оценки по результатам производственных практик, с одной стороны, и текущим состоянием отрасли в целом, с другой.

В этот период определяющее значение начинают принимать факторы конкретизации и осознание достигнутого уровня компетенции студентов как для будущих профильных специалистов. Поскольку этот процесс достаточно индивидуальный, но имеющий большую социальную и профессиональную значимость, то полезно рассмотреть его синергетическую составляющую [1; 2].

В отечественной и мировой методологической практике находим общие черты, отражающие фундаментальные параметры профессионального обучения как системы, которая находится под воздействием интенсивного инновационного развития производства, транснациональной специализации и конкуренции. Высшее профессиональное образование, связанное вековыми традициями и границами образовательного стандарта, имеет высокую инерционность и невысокую возможность оперативной адаптации в пределах «открытой системы» на основе, преимущественно, старого опыта, знаний и техники, а также не вполне ясный горизонт прогнозирования (5 лет) потребности специалиста данного профиля.

Образовательные открытые системы, как и любые системы вообще, имеют свою структуру, состоят из определенных, в том числе синергетических элементов, которые могут быть взаимосвязаны между собой. Известно, что взаимодействие различных элементов образовательной системы или ее подсистем направлено на достижение общей для системы цели, общего положительного результата. Эта цель - обучение, воспитание и развитие личности. Мерилом достижения этой цели является результат, который, в конце концов, отражен в личности выпускника, а не в безличных новообразованиях типа технологий обучения, методик воспитания, организации учебного процесса, создания материальной базы и т. д. Отдельные составляющие образовательной системы, в том числе и психологическая служба как подсистема, могут иметь свои специфические цели, но и они - лишь конкретизация и трансформация общей цели в специальные задачи (психологические, педаго-

\section{Baikal Research Journal}

электронный научный журнал Байкальского государственного университета 
гические, методические и т. д.). Можно сказать, что все элементы образовательной системы не просто включены в процесс взаимодействия, но и главная их особенность - взаимосодействие, направленное на достижение целей обучения, воспитания и развития личности специалиста.

В открытой системе основные элементы поддерживаются в определенном состоянии за счет непрерывного притока извне и (или) стока вовне, энергии или информации. Причем приток и сток обычно носят объемный характер, т. е. происходят в каждой точке данной системы. Также как и в нашем случае, постоянный приток (и сток) вещества, энергии или информации является необходимым условием существования неравновесных, неустойчивых композиций в противоположность замкнутым системам, неизбежно стремящимся (в соответствии со вторым началом термодинамики) к однородному равновесному состоянию.

В системах такого типа важна синергетическая компонента, где, по мнению ведущих отечественных исследователей, в целом синергетику как научную парадигму и нелинейный стиль мышления можно охарактеризовать следующими позициями:

- относительно эволюции систем - всякое явление - эволюционная необратимая стадия какого-либо процесса, содержащая информацию о его прошлом и будущем, допускающая многовариантность, тупиковые ветви, отклонения, которые могут быть, тем не менее, совершеннее современного состояния; развитие происходит благодаря неустойчивости; новое появляется в результате бифуркаций как случайное и непредсказуемое;

- относительно структуры и управления системами - системы являются зависимыми от процессов на вышележащих или нижележащих уровнях, в нелинейном мире малые причины могут порождать большие следствия; человеческие действия обречены на провал, если они не учитывают потенции среды и структур-аттракторов; управление сложными системами успешно лишь как нелинейное с учетом особенностей и тенденций их эволюции, а также эффективности малых воздействий [3-5].

Таким образом, при желании управлять такой системой потребуются прецизионные воздействия, формирующие элементы стабильной мотивации организационного процесса предварительно апробированного характера. Здесь, прежде всего, разделим причины, побуждающие выбрать ту или иную профессию, на внешние и внутренние. Внешние причины связаны с влиянием окружающей среды: мнением родителей, друзей, сверстников, желанием добиться внешнего успеха или страхом осуждения. За внутренние причины отвечаешь ты сам - их определяют твои способности, склонности, привычки и характер, и только они.

Паллиативное ранжирование мотивации представим как:

1. Лидер списка мотивов - престиж профессии. Мотив, в принципе, неплохой, однако в нем самом кроется ловушка. В наши времена престижны разного рода экономические и юридические специальности.

2. Второе место при выборе профессии занимает высокий заработок: кем бы ни работать, лишь бы хорошо получать.

3. Интерес к содержанию самой профессии, т. е. внутренняя причина ее выбора, находится лишь на третьем месте, а жаль.

4. В норме рост заработной платы напрямую зависит от роста квалификации. Профессии же, где планка заработной платы поднята изначально высоко, как правило, роста квалификации не предусматривают.

5. Условия труда тоже играют свою роль в выборе той или иной профессии. Впрочем, переменив место работы, иногда можно существенно изменить и условия труда (некоторые профессии это позволяют).

Легко заметить, что многие мотивы выбора той или иной профессии, в конце концов, оборачиваются ошибками, поскольку любая медаль имеет оборотную сторону, а

\section{Baikal Research Journal}

электронный научный журнал Байкальского государственного университета 
жизнь - это не только академические знания. Социализация в университете не сводится, конечно, лишь к передаче знаний об основах наук. Развитие человека в университете как личности и субъекта деятельности обязательно включает в себя развитие интеллекта, эмоциональной сферы, устойчивости к стрессорам, уверенности в себе и приятие себя, позитивного отношения к миру и приятие других, мотивации самоактуализации, самосовершенствования, самостоятельности, автономности.

Конечно, качество образования может существенно отличаться от вуза к вузу, как, собственно, во всех странах мира. Распространено мнение о том, что выпускники технических вузов слабо «заточены» под конкретные нужды предприятий. Заказчиков понять можно, им нужен инженер под конкретное оборудование и производство, но такой подход не назовешь дальновидным, поскольку он предполагает упрощенную схему подготовки инженеров. Такая схема подразумевает подготовку скорее бакалавров. Если же нужен инженер на высокотехнологичное, быстро изменяющееся производство или для проектирования и разработки новой техники и технологий, требуется другая подготовка - с большей ориентацией на специалиста расширенного профиля. Все это в системе российского инженерного образования есть и требует только некоторого упорядочения, чтобы инженер-разработчик был направлен и востребован в научно-исследовательских институтах и конструкторских бюро, а инженер-эксплуатационник - на конкретное производство. Сегодня возрастает внимание к решению проблемы инженерного образования как важнейшего элемента инновационного развития страны.

При сложной организационной и управленческой структурах современного высокотехнологичного производства для грамотного решения производственных проблем инженер должен хорошо владеть многими темами, в том числе, например, вопросами менеджмента и интеллектуальной собственности, знать иностранные языки. В вузах сложилась зарекомендовавшая себя практика получения студентами технических специальностей второго образования, что повышает ценность выпускаемого специалиста. Поэтому направления подготовки по менеджменту, технической экспертизе, проблемам интеллектуальной собственности в научно-технической сфере не должны считаться непрофильными для технических университетов, тем более для инженеров путей сообщения при соблюдении всех профессиональных требований, установленных образовательным стандартом для соответствующих направлений подготовки.

Рассматривая в прикладном варианте методологическую структуру учебного плана на каждую специализацию, обратим внимание на его компонент - дисциплины по выбору. В международной практике выбор дисциплин, формирующих требуемую мозаику компетенций и умений, необходимых для наполнения конкретной профессиограммы, один из основных моментов в организации учебного процесса. Одна из трудностей здесь - планирование учебной нагрузки преподавателей и их профильный состав. Непростым является и подбор студентом «букета» профильных дисциплин, поскольку их выбор усложнен необходимостью набора оценочных баллов различного характера и обязательности.

Исходя из этого, объективно возможен конфликт интересов - ситуация, при которой заинтересованность одной группы влияет на процесс принятия решения и, таким образом, приносит ущерб интересам общества либо отрасли, являющейся основным заказчиком специалистов.

В настоящее время выражение «конфликт интересов» используется достаточно широко. Конфликт интересов описывает ситуацию, с который мы можем сталкиваться ежедневно. В общем случае это ситуация, которая возникает в тех случаях, когда объект (вуз) действует одновременно в двух или нескольких различных ипостасях и цели этих действий расходятся между собой. Как компромиссный вариант

\section{Baikal Research Journal}

электронный научный журнал Байкальского государственного университета 
объединения интересов на рынке образовательных услуг в данном случае можно предложить создание временных экспертных групп, подтверждающих то или иное группирование профилей с установлением на период действия очередного поколения образовательного стандарта, соответствующего критерю оптимальности.

Верификацию рекомендаций в широкой практике (достоверность экспертной оценки) отражает коэффициент конкордации Кенделла, который, в общем, определяет степень согласованности мнений экспертов. Тем не менее, с возрастанием иерархии и соответственно ростом цены ошибки возникает дополнительно проблема отбора экспертов и их компетенционного тренинга. В настоящее время может быть использован метод, позволяющий проводить определение компетентности экспертов на базе аксиомы несмещенности, которая утверждает, что мнение большинства компетентно. Как следствие, наиболее компетентным считать того эксперта, расхождение мнений которого с мнениями других экспертов минимально. Документирование выбора возможно на основе решения соответствующих матриц, разрабатываемых в предшествующий или тренинговый период [6]. Однако развитие конфликта имеет определенный уровень вероятности, особенно при исчерпании потенциала саморегуляции (синергетической составляющей).

Эффективность работы по предупреждению и урегулированию конфликта интересов предполагает полное и своевременное выявление таких конфликтов и координацию действий всех заинтересованных сторон, в том числе советов образовательных программ. При этом условия и факторы конструктивного разрешения конфликтов начинаются с поиска общих или близких по содержанию точек соприкосновения в целях и интересах оппонентов, предполагают анализ как своих целей и интересов, так и целей и интересов другой стороны. Если стороны хотят разрешить конфликт, они должны сосредоточиться на интересах, а не на личности оппонента (рис.).



При разрешении конфликта сохраняется устойчивое негативное отношение сторон друг к другу. Оно выражается в отрицательном мнении об оппоненте и в негативных эмоциях по отношению к нему. Чтобы приступить к разрешению конфликта, необходимо смягчить это негативное отношение [7; 8]. Одновременно целесообразно перестать видеть в оппоненте врага, противника. Важно понять, что проблему, из-за которой возник конфликт, лучше решать сообща, объединив усилия. Этому способствует, во-первых, критический анализ собственной позиции и действий - выявление и признание собственных ошибок снижает негативное восприятие оппонента. Во-вторых, необходимо постараться понять интересы другого. Понять - не значит

\section{Baikal Research Journal}


принять или оправдать. Однако это расширит представление об оппоненте, сделает его более объективным. В-третьих, целесообразно выделить конструктивное начало в поведении или даже в намерениях оппонента. Не бывает абсолютно плохих или абсолютно хороших людей или социальных групп. В каждом есть что-то положительное, на него и необходимо опереться при разрешении конфликта.

Таким образом, образовательные системы, как и любые системы вообще, имеют свою структуру, состоят из определенных элементов, которые в конечном итоге взаимосвязаны между собой. Взаимодействие различных элементов образовательной системы или ее подсистем направлено на достижение общей для системы цели, общего позитивного результата. Достижение конечной цели любой образовательной системы является сложным процессом, жестко управляемый действующими стандартами, с одной стороны, и включающий элементы самоорганизации, с другой.

При развитии инновационных многокритериальных отраслей и технологий как, например, железнодорожный транспорт, необходимо в условиях полной управляемости предусматривать возможность оперативного согласования интересов как фирм и предприятий, так и возможностей конкретного университета. Все элементы образовательной системы включаются в процесс взаимодействия, но главной особенностью их связи является взаимосодействие с учетом не всегда успешно метризуемых факторов и параметров.

\section{Список использованной литературы}

1. Федоров И. Б. 20-летний опыт эффективного использования интеллектуального потенциала студентов Аэрокосмического факультета // Аэрокосмические технологии. 2004-2007 : материалы Всерос. и Междунар. науч.-техн. конф. (Реутов - Москва, 2004-2007 гг.) / под ред. Р. П. Симоньянца. - М. : Изд-во Моск. гос. техн. ун-та им. Н. Э. Баумана, 2008. - С. 10-12.

2. Бранский В. П. Теоретические основания социальной синергетики / В. П. Бранский // Петербургская социология. - 1997. - № 1. - С. 148-179.

3. Садовский В. Н. Общая теория систем Л. фон Берталанфи: некоторые итоги полувекового развития / В. Н. Садовский // Субъект. Познание. Деятельность. - М. : Канон+, 2002. - C. 633-646.

4. Войцехович В. Э. Математические теории синергетики / В. Э. Войцехович // Устойчивое развитие в изменяющемся мире : материалы Моск. синергет. форума, 27-31 янв. 1996 г. : тез. докл. - М., 1996. - С. 46.

5. Haken H. Principles of Brain Functioning: A Synergetic Approach to Brain Activity, Behavior and Cognition / H. Haken. - Berlin : Springer-Verlag, 1996. - 347 p.

6. Тюньков В. В. К модели адаптации управляющих воздействий для обеспечения надежности сложной конструкции при вероятных экстремальных воздействиях [Электронный ресурс] / В. В. Тюньков, О. А. Бочерова // Известия Иркутской государственной экономической академии (Байкальский государственный университет экономики и права). - 2012. № 2. - Режим доступа : http://brj-bguep.ru/reader/article.aspx?id=12280.

7. Тюньков В. В. Экономический риск-менеджмент : учеб. пособие / В. В. Тюньков. Иркутск : Изд-во Иркут. гос. экон. акад., 2001. - 520 с.

8. Шипилов А. И. Искусство конструктивно разрешать конфликты / А. И. Шипилов // Кадры предприятия. - 2002. - № 3. - С. 47-53.

\section{References}

1. Fedorov I. B., Simonyants R. P. Twenty-year experience of effective use of intellectual potential of Aerospace Department students. In Simonyants R. P. (ed.). Aerokosmicheskie tekhnologii. 2004-2007. Materialy Vserossiiskikh i Mezhdunarodnoi nauchno-tekhnicheskikh konferentsii (Reutov - Moskva, 2004-2007 gg.) [Aerospace Technologies. 2004-2007. Materials of All-Russian and International Research and Technology Conferences (Reutov - Moscow, 2004-2007)] Bauman Moscow State technical University Publ., 2008, pp. 10-12. (In Russian).

2. Bransky V. P. Theoretical grounds of social synergetics. Peterburgskaya sotsiologiya $=$ Petersburg Sociology, 1997, no. 1, pp. 148-179. (In Russian).

\section{Baikal Research Journal}

электронный научный журнал Байкальского государственного университета 
3. Sadovsky V. N. L. fon Bertalanffy General Theory of Systems: Some Results of Half-Century Development. Sub"ekt. Poznanie. Deyatel'nost' [Subject. Cognition. Activity]. Moscow, Kanon+ Publ., 2002, pp. 633-646. (In Russian).

4. Voitsekhovich V. E. Mathematical theories of synergetics. Ustoichivoe razvitie $v$ izmenyayushchemsya mire. Materialy Moskovskogo sinergeticheskogo foruma, 27-31 yanvarya 1996 g. [Sustainable development in the changing world. Materials of Moscow Synergetic Forum, Jan. 27-31, 1996]. Moscow, 1996, p. 46. (In Russian).

5. Haken H. Principles of Brain Functioning: A Synergetic Approach to Brain Activity, Behavior and Cognition. Berlin, Springer-Verlag, 1996. $347 \mathrm{p}$.

6. Tyun'kov V. V., Bocherova O. A. On model of control action adaptation for providing reliability of complex design under possible extreme conditions. Izvestiya Irkutskoi gosudarstvennoi ekonomicheskoi akademii (Baykalskii gosudarstvennyi universitet ekonomiki $i$ prava) $=$ Bulletin of Irkutsk State Economics Academy (Baikal State University of Economics and Law), 2012, no. 2. Available at: http://brj-bguep.ru/reader/article.aspx?id=12280. (In Russian).

7. Tyunkov V. V. Ekonomicheskii risk-menedzhment [Economic risk management]. Irkutsk State Economics Academy Publ., 2001. 520 p.

8. Shipilov A. I. Art of resolving conflicts in a constructive way. Kadry predpriyatiya $=$ Corporate Personnel, 2002, no. 3, pp. 47-53. (In Russian).

\section{Информация об авторах}

Тюньков Владислав Владилирович - доктор технических наук, профессор, кафедра вагоны и вагонное хозяйство, Иркутский государственный университет путей сообщения, 664074, г. Иркутск, ул. Чернышевского, 15, e-mail: tunkov@bk.ru.

Санина Людлила Валерьевна - начальник научного управления, кандидат экономических наук, доцент, кафедра менеджмента, маркетинга и сервиса, Байкальский государственный университет, 664003, г. Иркутск, ул. Ленина, 11, e-mail: glv2010@yandex.ru.

Санникова Елена Георгиевна - аспирант, кафедра вагоны и вагонное хозяйство, Иркутский государственный университет путей сообщения, 664074 , г. Иркутск, ул. Чернышевского, 15, e-mail: sannikova@irgups.ru.

\section{Authors}

Vladislav V. Tyunkov -Doctor habil. (Engineering), Professor, Chair of Railroad Cars and Rolling Stock, Irkutsk State Railway Engineering University, 15 Chernyshevsky St., 664074, Irkutsk, Russian Federation; e-mail: tunkov@bk.ru.

Lyudmila V. Sanina - Head of Department of Science, PhD in Economics, Associate Professor, Chair of Management, Marketing and Services, Baikal State University, 11 Lenin St., 664003, Irkutsk, Russian Federation; e-mail: glv2010@yandex.ru.

Elena G. Sannikova - PhD Student, Chair of Railroad Cars and Rolling Stock, Irkutsk State Railway Engineering University, 15 Chernyshevsky St., 664074, Irkutsk, Russian Federation; e-mail: sannikova@irgups.ru.

\section{Библиографическое описание статьи}

Тюньков В. В. Риск-менеджмент в синергетике учебного процесса на старших курсах университета при подготовке инженеров-специалистов / В. В. Тюньков, Л. В. Санина, Е. Г. Санникова // Baikal Research Journal. - 2016. - T. 7, № 4. - DOI : 10.17150/2411$\underline{6262.2016 .7(4) .22}$.

\section{Reference to article}

Tyunkov V. V., Sanina L. V., E Sannikova. G. Risk management in synergetics of educational process for university senior students in training specialists in engineering. Baikal Research Journal, 2016, vol. 7, no. 4. DOI : 10.17150/2411-6262.2016.7(4).22. (In Russian).

\section{Baikal Research Journal}

